\title{
IMPLEMENTACIÓN DEL PROGRAMA “MINUTO DE ORO” EN MAHOU SAN MIGUEL
}

\section{IMPLEMENTATION OF “MINUTO DE ORO” PROGRAM IN MAHOU SAN MIGUEL}

Lenny Fabiola León Montaño. EAE Business School, España.

Alexis Tatyana Rubio Osorio. EAE Business School, España.

Jessica Carmen Carolina Valle Miranda. EAE Business School, España.

Isabel María Cobreros Romera. EAE Business School, España.

\section{RESUMEN}

El propósito de nuestro trabajo de Máster es medir el impacto de la implementación de un programa mindfulness basado en la toma de consciencia del momento presente llamado "Minuto de Oro", (tan solo unos minutos al día puede ser suficiente para volver nuestra atención al momento de la experiencia presente, sin hacer juicios y con una actitud de aceptación). El programa está diseñado en forma de píldoras para realizar en la mañana de manera habitual y durante la tarde y noche de forma opcional, implementadas durante un periodo de 12 semanas dentro del departamento de operaciones y a través de las TOP SEM que realizan los trabajadores dentro del programa de excelencia en la empresa Mahou San Miguel. La investigación se ha llevado a cabo en dos localizaciones diferentes: la fábrica de producción sita en Alovera y en la sede central en Madrid. En cada una se ha estudiado tres grupos que se dividen en mandos Altos, medios y personal de fábrica o personal administrativo respectivamente, dependiendo de si es fábrica o sede. Se ha hecho la medición a través del CHEF o Cuestionario de habilidades específicas de felicidad, además de un cuestionario de preguntas que identifica el incremento de las habilidades de atención plena, aceptación, adaptación y compasión, con el fin de medir el impacto que tiene la implementación de la parada consciente o "Minuto de Oro" en la calidad de vida del personal de MSM, tanto en el ámbito profesional cómo en el personal.

PALABRAS CLAVE: Mindfulness, programa, minuto de oro, Mahou San Miguel, píldora.

\section{ABSTRACT}

The purpose of our project is to measure the implementation of a mindfulness program based on the awareness of the present moment, called "Golden Minute" (just some minutes per day may be enough to return the attention to the present experience, without making any judgments and with an attitude of acceptance). The program is designed in the form of pills to be carried out in the morning (mandatory), and in the afternoon and evening (optional) implemented during a period of 12 weeks within the operations department and through the TOP SEM meetings within the 
Excellence Program in Mahou San Miguel. The investigation is carried out in two different locations: the Alovera manufacturing plant and the headquarters. Three groups in each location, divided into senior managers, middle employees and manufacture or administrative personnel, respectively. The program is evaluated through the CHEF or Specific Skills Questionnaire as well as through a questionnaire to identify the progress in attention, acceptance, adapting process and compassion abilities and measure the impact of a conscious stop or "golden Minute" in the quality of life both professionally and personally in the Mahou San Miguel's population.

KEYWORDS: Mindfulness, program, minuto de oro (golden minute), Mahou San Miguel, pill.

\section{Cómo citar el artículo:}

León Montaño, L. F., Rubio Osorio, A. T, Valle Miranda, J. C. C. y Cobreros Romera, I. M. (2020). Implementación del programa "minuto de oro" en Mahou San Miguel. Revista de Ciencias de la Comunicación e Información, 25(2), 107131. doi: http://doi.org/10.35742/rcci.2020.25(2).107-131

\section{PARTE INTRODUCTORIA}

\subsection{Estado de la cuestión}

Dada la literatura y estudios existentes sobre la práctica de mindfulness y sus beneficios, se realizó una búsqueda de las investigaciones referentes a la implementación de mindfulness en el ámbito laboral, si bien no hay mucha información y artículos de cómo se debe llevar a cabo la implementación y diseño de un programa de mindfulness en dicho ámbito, hemos encontrado las siguientes investigaciones de implementación.

En la siguiente tabla mostramos los estudios mencionados:

Tabla 1. Resultado de investigaciones científicas

\begin{tabular}{|c|c|c|c|c|c|}
\hline $\begin{array}{l}\text { DATOS DEL } \\
\text { ESTUDIO / } \\
\text { PUBLICACIÓN }\end{array}$ & $\begin{array}{c}\text { AUTOR / } \\
\text { AFILIACIONES DEL } \\
\text { AUTOR }\end{array}$ & $\begin{array}{l}\text { OBJETIVO DEL } \\
\text { ESTUDIO }\end{array}$ & MUESTRA & CATEGORIA & RESULTADOS \\
\hline $\begin{array}{l}\text { Developing } \\
\text { leader through } \\
\text { Mindfulness } \\
\text { practice } \\
\text { Journal of } \\
\text { Management } \\
\text { Development. } \\
2020\end{array}$ & $\begin{array}{l}\text { Reitz, Megan } \\
\text { Waller, Lee } \\
\text { Chaskalson, Michael } \\
\text { Olivier, Sharon } \\
\text { Rupprecht, Silke } \\
\text { - Hult International } \\
\text { Business School - } \\
\text { Campus de } \\
\text { Educación Ejecutiva } \\
\text { Ashridge, } \\
\text { Berkhamsted, Reino } \\
\text { Unido } \\
\text { - Mindfulness Works, } \\
\text { Cambridge, Reino } \\
\text { Unido } \\
\text { - Consultor de } \\
\text { Investigación, } \\
\text { Hamburgo, Alemania }\end{array}$ & $\begin{array}{l}\text { El estudio examinó } \\
\text { como la } \\
\text { capacitación y la } \\
\text { práctica atención } \\
\text { plena puede } \\
\text { impactar en tres } \\
\text { capacidades } \\
\text { identificadas como } \\
\text { críticas para liderar } \\
\text { en el siglo XXI: } \\
\text { Resiliencia, } \\
\text { liderazgo en } \\
\text { contextos } \\
\text { complejos y } \\
\text { colaboración. }\end{array}$ & $\begin{array}{l}\text { Se realizó el } \\
\text { estudio de forma } \\
\text { controlado y no } \\
\text { aleatorio, se } \\
\text { seleccionó a } 57 \\
\text { líderes senior } \\
\text { (81\% mujeres) } \\
\text { que realizaron un } \\
\text { programa de " } \\
\text { Líder consciente" } \\
\text { de ocho } \\
\text { semanas. }\end{array}$ & $\begin{array}{l}\text { Implementación } \\
\text { de mindfulness o } \\
\text { atención plena } \\
\text { en el trabajo. }\end{array}$ & $\begin{array}{l}\text { Los resultados obtenidos sugieren } \\
\text { que los líderes ejecutivos pueden } \\
\text { aprender y desarrollar la atención } \\
\text { plena, siempre y cuando practiquen } \\
\text { durante al menos } 10 \text { minutos por día. }\end{array}$ \\
\hline
\end{tabular}




\section{IMPLEMENTACIÓN DEL PROGRAMA “MINUTO DE ORO” EN MAHOU SAN MIGUEL}

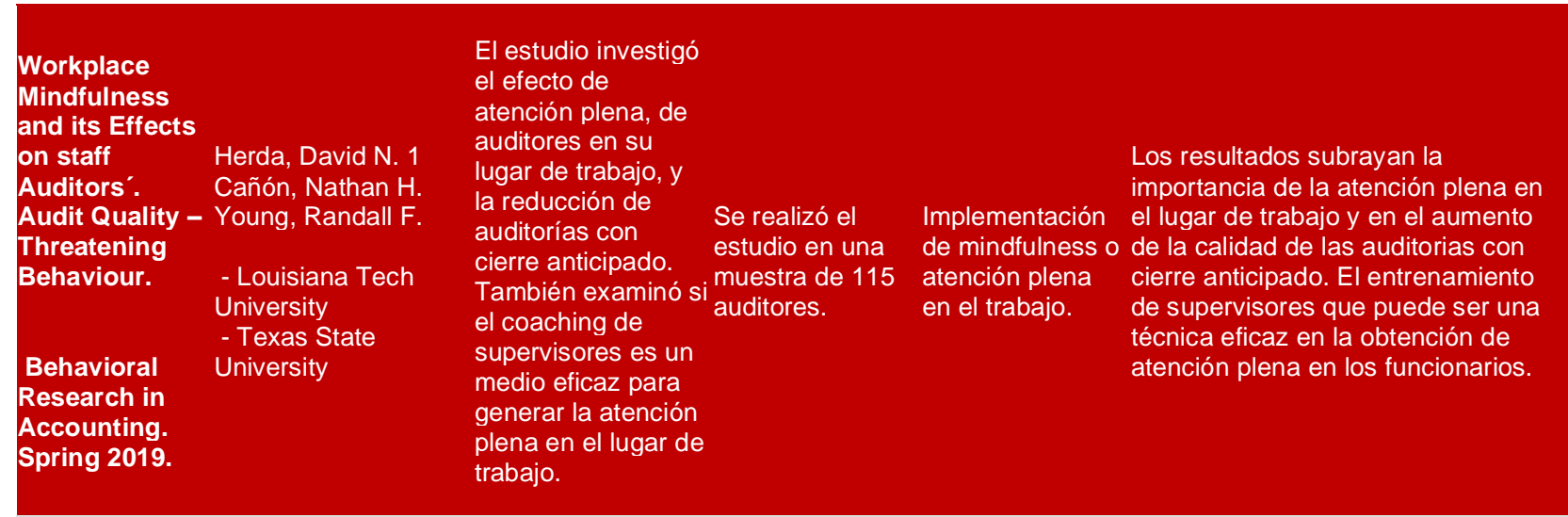

Reb, Jochen

Chaturvedi, Sankalp

$\begin{array}{ll} & \text { Narayanan, Jayanth } \\ \text { Leader } & \text { Kudesia, Ravi S. }\end{array}$

Mindfulness \& Kudesia, Ravi S.

\section{Employee}

Performance: - Lee Kong Chian

Mediation

Model of LMX

Quality,

School of Business,

Singapore

University, 50

Interpersonal Stamford Road,

Justice and 178899 , Singapur,

Employee

stress.

Singapur

- Imperial College

London, Londres,

Reino Unido

Journal of

Business

Ethics;

Dec2019

- National University

of Singapore,

Singapur, Singapur

- Temple University,

Filadelfia, PA, EE.

UU.
El estudio examinó

la relación entre la

atención plena del Estudios de

líder y el campo

desempeño de los

empleados a través - Estudio 1 : líde de los lentes de la triádico - datos justicia de empleados organizacional y las pares. relaciones líder-

miembro para tener - Estudio 2: líder mayor justicia diádico - datos interpersonal y de empleados.

menor estrés de los empleados.
Según las hipótesis encontraron que cuanto más conscientes son los líderes, mayor es la calidad de la relación entre el líder y el empleado, tal como lo percibe el subordinado. Además, descubrieron que cuanto Implementación más conscientes eran los líderes, de mindfulness o mejor se desempeñaban sus atención plena empleados, y que esta relación en el trabajo.

estaba mediada en parte por la calidad de LMX.

Encontraron que la relación entre la atención plena del líder y la calidad de LMX estaba mediada por el estrés de los empleados y la justicia interpersonal.

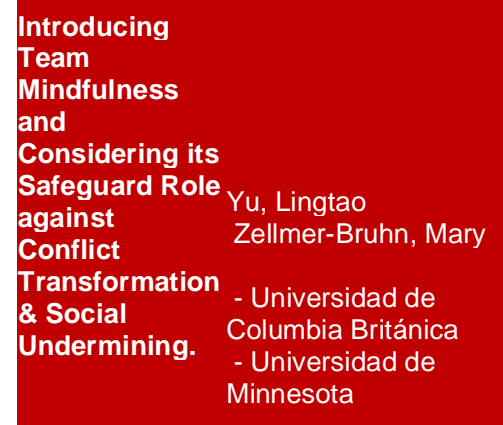

Academy of

Management

Journal .

Febrero de

2018.
Estudio 1

Desarrollo de

escala de

atención plena

del equipo $y$

establecer su

validez de

contenido.

Estudio 2:

El estudio tenía

como objetivo

Estudio de

campo con

introducir y validar equipos de MBA

una de EEUU,

plena del

equipo, y mostrar

su función $y$

significado como

protección contra

los aspectos

disfuncionales del

conflicto del equipo.

recopilaron datos

de dos clases de

MBA entrantes

(224 individuos,

que formaron 44

equipos)

Estudio 3:

Estudio de

campo con

equipos de salud

chinos,

accedieron a 50

equipos, que

constan de un

total de 318

empleados.
Los estudios sugieren que la

atención plena podría proteger a los equipos contra procesos

interpersonales negativos; también indicaron algunas limitaciones en el desarrollo de la investigación.

Implementación Esperan que la investigación de mindfulness o despierte un mayor interés en la atención plena atención plena, motive en el trabajo.

investigaciones más matizadas sobre el impacto total de la atención plena en las organizaciones y genere soluciones prácticas relacionadas con la atención plena que eviten los procesos interpersonales negativos en el trabajo. 


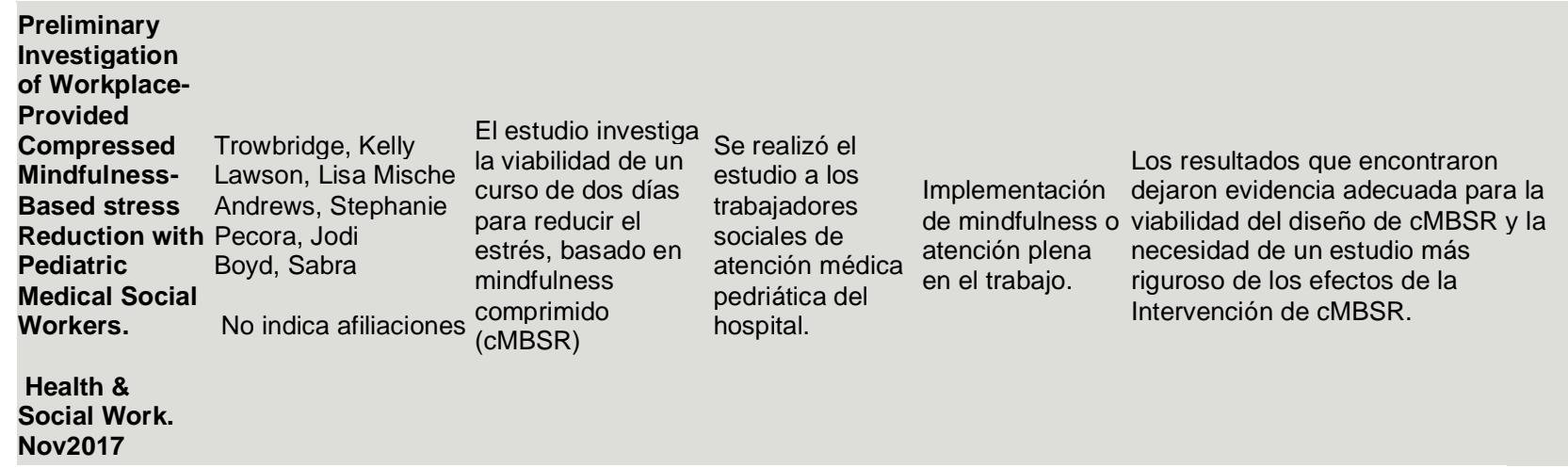

Fuente: Adaptado de Reitz , Waller, Chaskalson, Olivier, \& Rupprecht, 2020; Herda, Cañon , \& Young, 2019; Reb, Chaturvedi, Narayanan, \& Kudesia, 2019; Yu \& Zellmer-Bruhn, 2018; Trowbridge, Lawson, Andrews, Pecora, \& Boyd, 2017.

En las investigaciones encontradas se puede observar que la decisión de implementar mindfulness en el ámbito laboral, tenía como objetivo introducir la atención plena en el lugar de trabajo, medir el impacto y el efecto que genera en las organizaciones. Otras investigaciones se enfocaron en reducir los niveles de estrés de sus colaboradores e incrementar su eficiencia en el desempeño de funciones.

Jon Kabat-Zinn es, no obstante, quien popularizó e impulsó el uso de la meditación mindfulness como procedimiento para el tratamiento de trastornos psicológicos o psicosomáticos. En 1979 creó el Centro de mindfulness en la facultad de Medicina de la Universidad de Massachusetts para tratar aquellos casos y problemas clínicos que no respondían adecuadamente al tratamiento médico convencional. Desde entonces, el centro viene aplicando el MBSR a un amplio número de personas. Más de 15000 pacientes han seguido el programa en ese centro, además de otros muchos que se han aplicado en otros países. En ellas se han constatado, por ejemplo, la utilidad del programa para modificar ciertas funciones fisiológicas e inmunitarias (Davidson citado por Ramos En Re, 2012, p. 63).

Según la revisión de investigaciones y bibliografía sobre la práctica de mindfulness, se pudo constatar que tiene considerables efectos positivos, por lo que fueron incursionando e implementando en otros ámbitos, no solo en el ámbito médico donde inicialmente tuvo resultados considerables.

En función a los estudios e investigaciones encontradas y los resultados obtenidos en esas investigaciones, llegamos a la conclusión que se puede implementar mindfulness en MSM con un programa piloto "Minuto de Oro", el cual se enfocará en el diseño e implementación, para así desarrollar el nivel de atención plena, aceptación, compasión y adaptación en los colaboradores de MSM, este programa se implementará en la sede de Alovera y Titán, los grupos piloto estarán constituidos por mandos altos, medios y personal de fábrica o personal administrativo según la sede donde se desarrolle el programa.

Actualmente, vivimos en un mundo bastante cambiante y nos adaptamos a trabajar en multitareas, dónde se ha perdido la atención consciente de lo que estamos haciendo porque la ansiedad y los niveles de estrés han ido incrementando; el 
programa piloto "Minuto de Oro" para MSM busca optimizar la calidad de vida de sus colaboradores en el ámbito personal y profesional.

De esta manera, buscamos que el programa sea integral, que permita beneficiar a la empresa con la prevención, reducción del estrés laboral e incremento en los niveles de productividad, y también, se busca que sea beneficioso para los colaboradores y les permita mejorar su calidad de vida. Con la implementación buscamos medir el impacto generado dentro de MSM, para que más adelante ellos puedan evaluar la posibilidad de implementarlo en toda la organización.

\subsection{Descripción del problema}

La empresa en la que vamos a desarrollar el piloto "Minuto de Oro" se dedica al sector de la alimentación, más concretamente al sector de la cerveza en España. La gran relevancia de este sector para la economía española y europea, y la gran repercusión que tiene a nivel social, hace que los 4 grandes competidores presentes en el territorio español ejerzan una gran competitividad entre ellos.

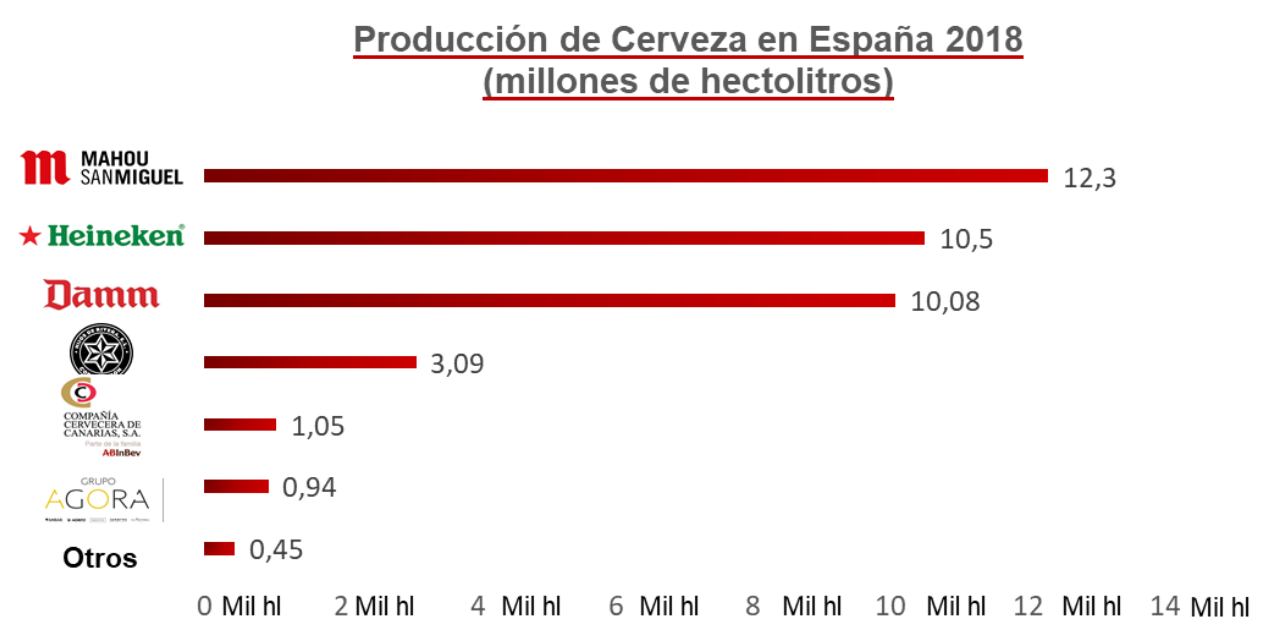

Figura 1: Producción de Cervezas en España 2018 (millones de hectolitros)

Fuente: Tomado de Datos del Informe Anual de Producción de Cerveza 2018

Si tensionamos esta competitividad con las variables externas sobre las que la organización no tienen ninguna influencia (precios de las materias primas, legislación vigente en cuanto al consumo, variación en los ámbitos de consumo de las diferentes generaciones en el mercado, etc), podemos afirmar que Mahou San Miguel ejerce su actividad en un entorno VUCA.

Es por esto que el concepto de entorno VUCA hace referencia a un contexto cambiante, y que, por lo tanto, supone un gran desafío hoy en día para las personas y las organizaciones.

Además, vivimos en la época de la multitarea: contestar mails y hablar por teléfono al mismo tiempo... el trabajo se acumula encima de la mesa y crece la ansiedad por intentarlo solucionarlo todo a la vez, una estrategia que conduce normalmente a no finalizar las tareas o llevarlas a cabo rápido y mal, es lo que (García Campayo, 2019, 
p. 11) define cómo atención parcial continua, la atención se dirige de forma secuencial, aunque cambiando muy rápidamente a ambas tareas.

Todo esto genera que los trabajadores pasen frecuentemente de eustrés a distrés, sin que la organización se dé cuenta, lo que genera falta de eficiencia en todo el ecosistema. La falta de eficiencia se debe principalmente a la inatención en las tareas, a ejercer la multitarea constantemente en nuestro día a día.

En estos entornos tan cambiantes y de multitarea, los niveles de falta de atención en la sociedad moderna actual son increíbles. Así, según (García Campayo, 2019, p. 11), se acepta en psicología que los niveles de inatención alcanzados en nuestro mundo contemporáneo son los más elevados de la historia de la humanidad.

Es por esto que la intención es la disminución del rendimiento en cualquier actividad que realizamos. Pero otro efecto, seguramente más importante, es el mayor stress que padece la persona no atenta, por dos razones: la primera es que tiene que esforzarse mucho más y tardar más tiempo para realizar cualquier tarea, obteniendo una menor eficiencia que las personas atentas. La segunda y principal es porque está pensando continuamente y eso es una fuente de stress inagotable. (García Campayo, 2019, p. 13).

Si aplicamos esta conclusión a un entorno laboral, podemos imaginar la cantidad de efectos indeseados tanto para el individuo (irritabilidad, incapacidad de relajarse 0 concentrarse, sentirse menos comprometido con la empresa), cómo para la organización (mayor absentismo, menor dedicación al trabajo y por ende retraso en los proyectos, lo que deriva en que la competencia se te pueda adelantar en la presentación de un producto, e incrementos en la inversión económica para cubrir todos estos retrasos, bajo rendimiento económico del personal, aumento de las quejas por parte de los clientes, y cómo consecuencia percepción de imagen negativa tanto dentro, como fuera de la organización).

Es por esto que creemos que la implantación de un proyecto o programa mindfulness en MSM favorecerá el rendimiento y el bienestar de toda la población organizacional (tanto dentro, como fuera de la oficina) generando un mejor clima laboral y promoviendo un liderazgo consciente y sistémico. Los beneficios para ambas partes (trabajador y empresa) son sustanciales en estos entornos con la implementación de un programa de atención plena.

\subsection{Hipótesis y Objetivos}

\subsubsection{Objetivo de estudio}

El objetivo de nuestro proyecto es diseñar un programa de mindfulness llamado "Minuto de Oro" para la empresa Mahou San Miguel e implementarlo dentro del micro máster "Somos Mahofulness" para mejorar el desarrollo de la atención plena, aceptación, adaptación y compasión de los trabajadores.

Objetivos específicos:

1. Diseñar un programa piloto basado en Mindfulness para el desarrollo de la atención concentrada en las reuniones Kaizen de MSM. 
2. Desarrollar 37 píldoras para la mejora de la atención concentrada, aceptación, adaptación y compasión.

3. Medir el impacto de la implementación del programa piloto de MO de los trabajadores de MSM para identificar su grado de atención concentrada.

\subsubsection{Hipótesis}

En este sentido y partiendo de lo expuesto, se formulan las siguientes hipótesis respecto a la implementación del programa "Minuto de Oro" y se espera:

Nuestro proyecto de fin de máster permitirá que el diseño e implementación del programa de mindfulness "Minuto de Oro" dentro del micro máster "Somos Mahofulness" mejore el desarrollo de la atención plena, concentración, adaptación y compasión de los trabajadores de Mahou San Miguel.

1. El diseño del programa $M O$ incrementará la concentración en las reuniones TOP SEM que se desarrolla dentro del programa Kaizen.

2. La utilización de las píldoras mejorara los niveles de atención concentrada, aceptación, adaptación y compasión en los trabajadores.

3. La práctica del programa $\mathrm{MO}$ incrementará el grado de atención concentrada de los participantes en el estudio.

\subsubsection{Objeto de estudio}

Diseño e Implementación del piloto "Minuto de Oro", programa de mindfulness, en empresa líder del sector de la alimentación, que desarrolla su actividad en un entorno VUCA y en una época de inatención. Ambos factores provocan que la población MSM pueda sufrir estrés. De cara a validar si un programa de mindfulness puede ayudar a canalizar el distrés, mejorar la atención concentrada, aceptación, adaptación y aumentar la calidad de vida de los trabajadores y la eficiencia de la empresa, se ha diseñado e implementado el "Minuto de Oro".

\section{BASES TEÓRICAS}

\subsection{Antecedentes del estudio}

En las tradiciones orientales se dice que la mente es el sexto sentido, y no porque tenga poderes paranormales, sino porque es igual que los otros sentidos. Podemos pensar voluntariamente, por ejemplo cuando pensamos en las vacaciones 0 preparamos una clase para nuestros alumnos, pero si no pensamos voluntariamente, la mente no dejará de generar pensamientos de forma involuntaria, porque no puede dejar de pensar. (García Campayo, 2019, p. 77),

Según García Campayo (2019, pag. 77), la función del diálogo interno es interpretar todo lo que nos ocurre, dar continuidad y sentido a nuestras experiencias, otorgándonos una sensación de estabilidad en el tiempo, y de identidad.

Según las investigaciones, el cerebro humano consume entre un 20 y un $25 \%$ del oxígeno y del riego sanguíneo en todo nuestro organismo. Estas elevadas necesidades son razonables debido a la complejidad del funcionamiento de nuestra 
mente. Gracias al perfeccionamiento de las técnicas de neuroimagen, se ha descubierto que este consumo de oxígeno y riego sanguíneo no desciende cuando no estamos haciendo nada. ¿Cómo es posible? La explicación es que la mente siempre está trabajando. (García Campayo, 2019, p. 75, pag. 76),

Cómo hemos experimentado todos, la mente mantiene un constante diálogo con nosotros mismos, dónde comenta nuestras expectativas, el mundo que nos rodea, etc., lo que muchas veces es una fuente de sufrimiento, por preocuparnos por el futuro o recordar situaciones en el pasado. $Y$ es aquí donde entra el constructor de mindfulness.

Cuando somos conscientes de lo que estamos haciendo, pensando o sintiendo, estamos practicando mindfulness. Lo que sucede es que habitualmente nuestra mente se encuentra vagando sin orientación alguna, saltando de unas imágenes a otras, de unos a otros pensamientos. El primer efecto de la práctica de mindfulness es el desarrollo de la capacidad de concentración de la mente. El aumento de la concentración trae consigo la serenidad nos conduce a un aumento de la comprensión de la realidad (tanto interna como externa) y nos aproxima a percibir la realidad (Simón, 2007, citado por Ramos, Recondo, Enriquez, pag. 59).

Cómo señala García Campayo, la psicología actual considera que existen dos formas básicas de funcionar de la mente humana, los modos "Hacer" y "Ser", que son característicos, pero no específicos del pensamiento occidental y oriental respectivamente. Se basan en premisas absolutamente diferentes. (2019, pag. 19), Nuestro mundo occidental está basado en la creencia de que la felicidad está fuera de nosotros, en la búsqueda continua de objetivos, y esto no es solamente una de las mayores causas de stress a la que estamos sometidos, sino una de las mayores causas de infelicidad en nuestra sociedad actual.

El modo hacer de la mente se asocia a la visión del "yo biográfico", porque los objetivos que nos marcamos se asocian a las etiquetas o descripciones de nosotros mismos que hemos ido desarrollando a lo largo de la vida y con la que nos identificamos y que mantenemos continuamente debido al diálogo interno. (García Campayo, 2019, p. 20),

En cambio, en el mundo oriental se cree que la felicidad no está fuera de nosotros, sino dentro. Lo importante es el presente ya que ni el pasado ni el futuro existen, y así no hay nada que obtener, nada que perseguir. La forma de alcanzar este estado de la mente es a través de la aceptación, que es la principal cualidad que se desarrolla con la práctica del mindfulness. (García Campayo, 2019, pag. 21).

Esta dicotomía entre el mundo hacer y el mundo ser se puede apreciar de mejor manera en la siguiente tabla: 
Tabla 3: Visión Occidental y Oriental del mundo y correlación con el modo de la mente y el tipo de Yo

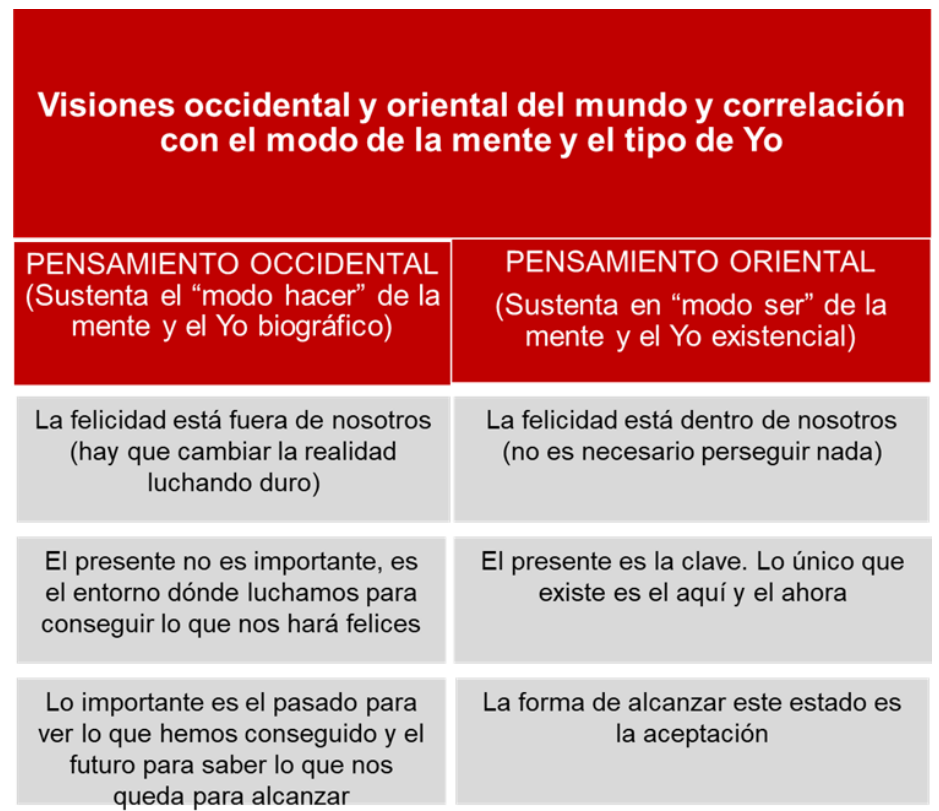

Fuente: Tomado de García Campayo , J. (2019). Mindfulness: Nuevo manual Práctico: El camino de la atención plena. España: Siglantana, p. 18.

Ser mindful en todos los sentidos de este término (hacer las cosas de una manera deliberada y a consciencia, ser abiertos y creativos con las posibilidades, ser consciente del momento presente sin emitir juicios), es actuar en un estado de consciencia que nos hace flexibles y receptivos, y nos permite estar presentes. Se ha demostrado que estar plenamente presente mediante la práctica de la atención consciente o mindfulness es fundamental para afrontar con entereza los retos que nos plantea la vida. (Siegel, 2012, pag. 29).

Citando de nuevo a García Campayo entendemos mindfulness como un proceso cognitivo complejo, no narrativo, que algunos autores han denominado modo ser, en contraposición con la forma habitual en la que funciona nuestra mente en la vida diaria, o "modo hacer". (2019, pag. 19),

Consideramos el modo hacer con la consecución de objetivos, metas y planes. La mente siempre está ocupada analizando el pasado o el futuro sin prestar atención a la tarea presente.

\subsection{Bases Teóricas}

\subsubsection{Minfulness}

\subsubsection{Historia y antecedentes}

Para García Campayo, mindfulness tiene dos significados:

- Un estado de la mente: esta es la aceptación más utilizada. Define un estado y un rasgo de la mente humana, que ha sido descrito por todas las religiones y culturas. Dicha cualidad de la mente está presente en todos los individuos 
en mayor o menor intensidad, y aparece en la población siguiendo una distribución normal, es decir, en forma de campana de Gauss. Este estado, que siempre se puede entrenar en cualquier persona, se asocia a un gran bienestar físico y psicológico, y por eso esta técnica psicológica se está utilizando ampliamente a nivel internacional.

- La técnica psicológica que permite desarrollar mindfulness: mindfulness es una psicoterapia cómo tal, que puede usarse tanto para el tratamiento de enfermedades, como para la prevención del malestar psicológico y aumentar el bienestar psicológico. La práctica de la atención plena enseña a relacionarse de una forma diferente con pensamientos y emociones. La idea sería no quedarse "atrapado", no identificarse con los pensamientos, de manera que no nos afecten. De esta forma, lo importante, no es el contenido positivo o negativo de los fenómenos mentales, sino nuestra relación con ellos.

Aunque algunos de sus términos y técnicas provienen de las tradiciones religiosas orientales y, específicamente, del budismo, mindfulness es una técnica secular, sin ninguna reminiscencia religiosa o cultural, y que posee una sólida base científica. García Campayo (2019, pag. 41, 42).

Todas las definiciones de mindfulness se retroalimentan unas de otras, y es por eso, que, en el diseño de este programa, hemos utilizado básicamente las definiciones de Kabat-Zinn y de Javier García Campayo porque consideramos que son las que más se vinculan con la hipótesis 1 por que el diseño y desarrollo del programa MO están basados en la atención plena para incrementar la concentración de los colaboradores de MSM. En el ámbito laboral la personas realizan un trabajo de multitareas lo cual hace que pierdan concentración de lo que está sucediendo en el presente y esto conlleva tener pérdida de concentración lo que se busca con el programa MO de hora es que las personas puedan ser más conscientes.

\subsubsection{Atención plena cómo estado de la mente}

Según García Campayo (2019), todas las definiciones de mindfulness deben incorporar las siguientes características:

Capacidad de estar atento - El individuo no está distraído, somnoliento o indolente, sino atento y perfectamente centrado en lo que está viviendo. Pero en un estado de atención relajada, no tensa o excitada. (2019, pag. 42),

El concepto de capacidad de estar atento es muy importante en nuestro estudio ya que la mayoría de las píldoras diseñadas, como se podrá apreciar más tarde, se basan en desarrollar esta característica esencial de la atención plena.

En el presente - Uno puede estar atento en el pasado, echándolo de menos (fenómeno que ocurre en la depresión), o centrado en el futuro, temiendo algo que va a ocurrir en él (circunstancia que ocurre en la ansiedad). En mindfulness, el sujeto está exclusivamente en el fenómeno presente. Por eso, es casi inevitable que sea muy consciente de su cuerpo, incluida la respiración, porque está siempre en el presente. El desarrollo de la consciencia corporal es un fenómeno clave en el desarrollo de mindfulness. (2019, pag. 42 y 43) 
Sin duda, el desarrollo de esta característica es una de las más importantes a desarrollar para el ámbito laboral a la hora de gestionar la tarea de manera efectiva, eficiente y enfocada al cuidado del detalle, pero sin ocupar mucho tiempo en el desarrollo de la misma, y esta premisa es una de las bases del método Kaizen.

Con aceptación - Mindfulness facilita no juzgar, criticar o estar a disgusto con la experiencia presente, sino aceptarla de una forma radical, sin esperar que sea diferente a como es. Aquí aceptación es diferente de resignación o pasividad; el sentido es de apertura y curiosidad no-crítica ante cada experiencia. Cualquier elemento de no aceptación que exista en la experiencia nos hará perder el estado de mindfulness. Esta es la forma más sutil de no estar en mindfulness.

(2019, pag. 43)

Intencional - Entrar en un estado de mindfulness constituye un ejercicio de voluntad, intencional, al menos al principio de la práctica. Con el tiempo, el proceso se vuelve natural y se puede estar en este estado la mayor parte del tiempo. (García Campayo, 2019, pag. 43).

Para extractar el contenido, toda definición de mindfulness debe considerar dos componentes fundamentales:

Autorregulación de la atención: permite mantenerse concentrado en la experiencia inmediata, facilitando un mayor reconocimiento de los fenómenos corporales, sensoriales, emocionales y mentales. (García Campayo, 2019, pag. 43).

La autorregulación de la atención plena en entornos multitarea es uno de los pilares del Sistema Kaizen con el que se trabaja en Mahou San Miguel. Este apartado se desarrollará en el marco práctico del estudio.

Orientación abierta hacia la propia experiencia: se caracteriza por la curiosidad y la aceptación, lo que implica la capacidad de reconocer la realidad cruda de los fenómenos, libre de nuestros filtros cognitivos. (García Campayo,2019, pag. 43).

Este hecho es imprescindible para adaptarse a un entorno laboral volátil, de constante cambio y que requiere uno de los pilares más importantes de hoy en día en los entornos VUCA, la innovación. Sin esta orientación de manera abierta hacia la propia experiencia, la creatividad se ve mermada por el hecho de no poder adaptarnos a todas las idas y venidas el mercado. Una empresa que no crea 0 innova se ve advocada al fracaso en los tiempos presentes.

Basándonos en los fundamentos de la práctica de mindfulness que hace Kabat- Zinn (1990, citado por Ramos, Recondo, Enriquez, pag. 64), existentes siete factores relacionados con la actitud que constituyen los principales soportes de la práctica de atención concentrada. Para el desarrollo de las píldoras y los videos de Javier García Campayo de los que está compuesto nuestro programa "Somos Mahoufulness", que veremos en la parte práctica de esta investigación, hemos utilizado cada uno de estos pilares de los que está compuesto este constructo. Es por ello, que además de utilizar la definición de Kabat- Zinn antes mencionada, hemos añadido parte de la descripción que hace García Campayo (2019) de cada uno de ellos. 


\subsubsection{Beneficios de mindfulness}

Desde de la fundación del programa MBSR fundado por Jon Kabat-Zinn para la reducción del stress utilizando la técnica de mindfulness, se han llevado acabo muchos estudios sobre los beneficios de la práctica en diferentes entornos sociales. Según García Campayo (2019) aquellos ámbitos en los que esta técnica se ha mostrado efectiva se pueden resumir en tres:

\section{Sanitario}

- Tratamiento de enfermedades médicas: dolor crónico, fibromialgia, enfermedades cardiovasculares, cáncer, enfermedades crónicas, etc.

- Tratamiento de enfermedades psiquiátricas: depresión, ansiedad, adicciones, trastornos de conducta alimentaria, trastorno obsesivo, trastornos de personalidad, etc.

- Prevención del stress y del malestar psicológico/Desarrollo de bienestar psicológico.

- Alargamiento de la esperanza de vida.

\section{Educativo}

- Aumento de la concentración y del rendimiento académico.

- Mejora de la regulación de emociones y de las relaciones interpersonales.

- Potencia el ambiente positivo en las aulas (por ejemplo, se ha utilizado para prevenir el bullying).

\section{Empresarial y laboral}

- Reducción y prevención del estrés laboral y de otros riesgos psicosociales, como el quemado profesional o burnout, y el acoso psicológico o mobbing.

- Aumento de la satisfacción laboral y mejora en el entorno.

- Mayor rendimiento laboral.

- Mejora de la empatía hacia clientes/colaboradores y la satisfacción de éstos.

\subsubsection{Aceptación}

\subsubsection{Antecedentes}

La palabra aceptación proviene del latín acceptatio, según la Real Academia Española (2001) Aceptación es la acción y efecto de aceptar, aprobación, aplauso; también hace referencia a la aceptación de personas que es la acción de favorecer o inclinarse a unas personas más que a otras, por algún motivo o efecto particular, sin atender al mérito o a la razón.

Aceptación es una apertura a la realidad sin desear que las cosas que están ocurriendo cambien. A menudo la aceptación sólo llega tras períodos de negación, ira, culpa y otras emociones, en un proceso habitual de curación. La aceptación no implica que nos gusta todo lo que está ocurriendo, ni que hay que adoptar una actitud pasiva hacia todo, ni que tienes que abandonar tus valores, tolerar la injusticia o renunciar a cambiar el mundo y a ti mismo. La aceptación permite ver las cosas como son en ese momento, sin imponer nuestras ideas sobre cómo debería ser, sin cambiarlas porque, como ya está ocurriendo, no podemos hacerlo. Todo lo 
que aparezca en la mente está bien. Acepta tus emociones y pensamientos, por desagradables, negativos o vergonzantes que parezcan. No te juzgues ni te critiques por tener tales pensamientos, o por los fracasos que hayas tenido en la vida, y que aparezca en la meditación. (Kabat-Zinn citado por García Campayo 2019, p.58). El autor le da un enfoque integral, invita a aceptar la situación, pensamiento, emoción, circunstancia; permitiéndole al individuo desapropiarse y no juzgar, así el periodo de negación es más corto, por tal motivo consideramos desarrollar la aceptación de los colaboradores de MSM.

Hayes 2003 sugiere que la aceptación implica "experimentar eventos totalmente y sin defensa, tal y como son", y señala que los pacientes en la práctica pueden exagerar la importancia de cambiar los síntomas desagradables, sin reconocer la importancia de la aceptación. (Hayes citado por Ramos En Re, 2012, p. 82)

Jeff Foster (2008) si bien no tiene una teoría basada en mindfulness sin embargo en su libro "Mi más profunda aceptación" tiene una propuesta bastante interesante donde relaciona al océano con la aceptación: El océano no acepta unas olas y rechaza otras, es una gran verdad y se puede decir que en nuestras vidas tenemos una realidad a pesar de que a veces rechazamos cosas que no nos agradan pero no podemos cambiarlas así que no nos sirve de nada rechazarlas. Para Foster aceptación significa ver la realidad, ver las cosas como son realmente, y no como esperamos o deseamos que sean, le quitas poder a las expectativas o intentar cambiarlo.

Mindfulness como técnica invita a la aceptación de la experiencia presente, aun cuando se persigue cambiar dicha experiencia, y, para ello, propone disminuir la incidencia del lenguaje como elemento distorsionador de la experiencia real. Desde la aceptación los hechos pueden plantearse su camino. De este modo, mindfulness resulta una técnica adecuada para trabajar en contextos terapéuticos y educativos. La clave de la eficiencia del mindfulness reside en la combinación de la atención a momento presente junto con la actitud no valorativa que implica curiosidad y aceptación (Bishop et al, citado por Ramos En Re, 2012, p. 125).

Los aportes de los autores fueron relevantes para la investigación y nos permite diseñar las píldoras "Minuto de Oro" donde se tiene un apartado de píldoras de aceptación, se puede decir que aceptación es recibir las cosas como, sin juicios, sin intentar cambiarlas, porque es la realidad y así vivir en libertad, por tal motivo se consideró diseñar las píldoras para específicamente fortalecer la aceptación, ya sea de una emoción, situación, realidad, sin juicios, simplemente aceptarlas como son, para que los colaboradores de MSM incrementen los niveles de aceptación y mejoren la relación laboral, el manejo de situaciones complicadas y la gestión de emociones en el ambiente laboral.

\subsubsection{Adaptación}

\subsubsection{Historia y beneficios}

Dentro de las nociones generales que podemos mencionar sobre este término, tenemos la definición que recoge el Diccionario de la Real Academia Española, 
donde señala a la adaptación como acción y efecto de adaptar o adaptarse (Real Academia Española, s.f.).

La adaptación es la cualidad de acomodarse a una situación determinada. El hombre es un ser eminentemente adaptativo.

Como es lógico, nuestra adaptación es un proceso que se ha ido consolidando a lo largo de la evolución. Durante miles de años hemos incorporado técnicas para habituarnos a todo tipo de situaciones. La invención del fuego, de la rueda, las matemáticas o la agricultura son creaciones humanas que dan respuesta a unas necesidades concretas. Es la inteligencia del hombre y su capacidad de resolver problemas lo que permite que nos adaptemos con relativa facilidad.

Los cambios tecnológicos y sociales provocan que tengamos que activar nuevas estrategias para no quedar desubicados. De alguna manera, la vida es un cambio permanente, que empuja a los individuos a encontrar una adecuada acomodación a las circunstancias que van apareciendo.

No hay que pensar que la adaptación es algo inmediato y fácil de realizar. Por lo general, es necesario superar un periodo de transición, en el que se supere el antiguo sistema y empieza una familiarización paulatina con el nuevo modelo. Pongamos como ejemplo a los niños pequeños. Cuando dejan de estar con sus padres y comienzan a ir al colegio hay una etapa de dificultad. Durante algún tiempo suelen llorar y manifiestan su rechazo a las aulas y a la novedosa situación. Se trata de un periodo normalmente breve, ya que rápidamente se habitúan al cambio. (Editorial Definición MX, 2013)

Basado en el texto citado, la cualidad que posee el ser humano para poder cambiar de un estado a otro, de acomodarse, con el objetivo de mantener la supervivencia en cualquier situación (como aquellas que marcan las condiciones generales de la vida) que le acontece es una característica notable que le permite ser flexible ante cualquier situación o circunstancia que vulnere su capacidad para vivir, la amenace o represente en su análisis una mejora para seguir evolucionando. Un elemento especial que interviene en la capacidad de acomodarse con relativa facilidad es la inteligencia que posee y mediante la cual (además de considerar otros elementos que añaden dinámica para seguir evolucionando) da respuesta a muchas necesidades concretas. La vida es un continuo de situaciones que en su beneficio o en los tan variados peligros que se presentan marcan experiencias gratas o dolorosas, pero que afrontadas de una manera que permitamos continuar nuestra vida aprendiendo y superándolas hace posible empujarnos a una adaptación. El mismo ser humano incluso es también partícipe de que nos impulse a cambiar y a adaptarnos debido a su jerarquía en la sociedad e influencia en el entorno, como por ejemplo aquellos cambios tecnológicos, sociales o de otra índole que nos invita a ejercer aquella plasticidad de nuestra naturaleza ante dichas situaciones y todo ello como consecuencia de la aplicación de la inteligencia en nuestras vidas para precisamente adaptarnos, superar y satisfacer necesidades. Es evidente que se requiere de un periodo de transición para salir de un estado y llegar a otro y su duración e intensidad dependerá de la vivencia de cada persona en el caso que seamos afectados por el cambio como en aquella que es capaz de transformar su entorno y que requiere tiempo para su aplicación y su uso en la sociedad. La 
celeridad en nuestra capacidad de acomodarnos puede ir variando en la medida que envejecemos.

\subsubsection{Compasión}

\subsubsection{Antecedentes}

Dada la importancia de la práctica de la compasión dentro de nuestro programa "Minuto de Oro" es indispensable desarrollar en profundidad su definición, para diferenciar lo que es compasión de lo que no es, además de recorrer el concepto a través de las diferentes disciplinas que lo estudian. La etimología de esta palabra

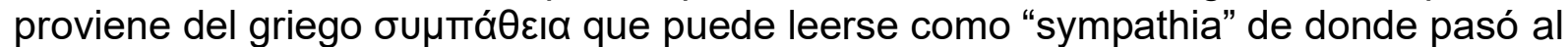
latín como "cumpassio" vocablo compuesto, integrado por "cum" = "con" y por el verbo "patior" = "padecer". De esta manera, la compasión es un sentimiento propio del hombre que le importa solidarizarse con el dolor ajeno, comprenderlo y compartirlo para intentar aliviarlo. (DeConceptos, 2020) Es un concepto muy complejo y diverso ya que se ha tratado de explicar desde diferentes disciplinas y culturas, abriendo las puertas a muchas interpretaciones según el contexto en el que es adoptado.

En español, la palabra compasión proviene de la palabra latina compati "sufrir con". El diccionario de la Real Academia Española define la compasión como el sentimiento de conmiseración y lástima que se tiene hacia quienes sufren penalidades y desgracias. En esta definición, fuertemente enraizada con la tradición judeocristiana, predomina el sentimiento de lástima. Lo que implica una sensación de superioridad hacia la persona que sufre, García Campayo (2019). En este sentido existe una tendencia a identificarse con las emociones de los demás, pero de una manera pasiva, donde se experimenta tristeza y lastima, pero no se especifica ningún interés por cambiar o mitigar el sufrimiento ajeno.

\subsubsection{Diferentes teorías}

Por su parte desde la psicología, una de las definiciones más usadas es la de Goetz y Cols (2010) la define como el sentimiento que surge al presenciar el sufrimiento de otro y que conlleva un deseo de ayudar. Otra definición es la de Paul Gilbert (2015): La profunda conciencia del sufrimiento de uno mismo y del de otros seres, junto con el deseo de ayudar a evitarlo. Simón (2014) habla de dos elementos claves en la compasión: uno es la sensibilidad al sufrimiento de los otros y de uno mismo y, por otro lado, el compromiso de aliviar ese sufrimiento. En este sentido la compasión es una emoción que se genera ante el reconocimiento del sufrimiento ajeno y provoca un impulso dirigido a mitigar el dolor que percibimos.

Gilbert, (2009) nos dice que para desarrollar la compasión es necesario practicar la atención hacia el sufrimiento de los demás. De acuerdo con Gilbert, existen algunos pasos para esto, entre ellos entender al otro, es decir, tener empatía; sentir con el otro, es decir, simpatía y actuar. Para esto es necesario primero profundizar en estos dos conceptos ya que, aunque pueden servir para explicar cómo desarrollar la compasión muchas veces son erróneamente empleados para definir el concepto de compasión. 
Por un lado, el termino simpatía significa una inclinación afectiva entre personas generalmente espontánea y mutua, es decir, que sientes lo que le ocurre a la otra persona, pero no necesariamente lo comprendes. En cambio, la empatía va un poco más allá, ya que además requiere de un proceso de entendimiento y comprensión. Según, lo define el Diccionario de la Real Academia Española, la empatía es la capacidad que tenemos de ponernos en el lugar de alguien y comprender lo que siente o piensa. Es decir, empatizamos con las emociones de los demás y nos conectamos con su situación, pero no necesariamente significa que tenga un efecto movilizador o que lleve al individuo a actuar. La compasión por su parte, si busca un objetivo definido: mejorar la situación del otro.

De esta manera la compasión es algo más que la empatía, que es la capacidad de entender la conducta y los sentimientos de los demás. La compasión se diferencia de ella porque no solamente comprendemos el sufrimiento que percibimos, sino que nos despierta un impulso de realizar una acción encaminada a contrarrestarlo o anularlo. También es algo más que la simpatía, porque esta es una reacción que nos lleva a sentir la emoción que está sintiendo el otro. Así, cuando percibimos el sufrimiento de alguien, podemos sufrir con él; pero la compasión conlleva, además, el impulso hacia la actuación para eliminar o disminuir el sufrimiento.

Otros términos comúnmente relacionados con la compasión que designan conceptos diferentes según lo expresa Simón (2014) son el contagio emocional y el altruismo. Por un lado, el contagio emocional hace referencia a experimentar las mismas emociones del otro, pero de manera involuntaria y fusionándose emocionalmente con él. Ocurre en personas con dificultad para el manejo de sus emociones y que, por ello, son fácilmente influenciables. Por el contrario, el altruismo es una conducta que beneficia a otros, aunque puede ser perjudicial para uno mismo. García Campayo (2019).

Como podemos ver hay muchos conceptos que pueden ser fácilmente relacionados con el término de compasión. De la misma manera, Neiff (2003) también explora el término de autocompasión como: Afecto, amabilidad y comprensión hacia uno mismo cuando se experimenta sufrimiento, en lugar de autocriticarse, culparse o negar el propio dolor. En otras palabras, se trata de comprender el momento presente, esa situación que nos genera sufrimiento y angustia, pero comprenderla, entenderla y aceptarla desde el amor y la amabilidad, sin criticas ni reproches.

Otra definición de la autocompasión la da Neff (2003) sugiere: estar abierto y movido por nuestro propio sufrimiento, experimentando sentimientos de cariño, de bondad hacia uno mismo, tomando una actitud de entendimiento hacia los fallos y las incompetencias propias que no juzga y reconociendo que nuestra experiencia es parte de la experiencia de toda la humanidad. Esta autora propone tres elementos primarios en la autocompasión: cariño hacia nosotros mismos, darnos cuenta de que somos parte de la humanidad y la conciencia plena (mindfulness).

La conciencia plena o mindfulness nos ayuda a percibir nuestro sufrimiento, acercarnos a él y aceptarlo. Tomar consciencia de que podemos compartir y vivir las mismas virtudes y debilidades que cualquier otro ser humano nos permite poner en perspectiva nuestro propio sufrimiento y considerar sin llegar a juzgar la parte de responsabilidad que tenemos en él, que es la misma que cualquier otro individuo 
tendría en nuestro caso. Finalmente, el amor hacia nosotros mismos nos permite tratarnos con el mismo cariño y cuidado que podemos sentir y ofrecer hacia otra persona querida.

De esta manera, en mindfulness uno de los modelos más utilizados es el de Kristin Neff y su grupo que habla de hacerse consciente del sufrimiento propio y de los otros, sin juicios ni críticas. No se niega el sufrimiento, ni se huye de él, ni se queda atrapado en él. No sé sobre identifica con el sufrimiento o si no la compasión se convierte en empatía. Neiff (2003)

Para García Campayo (2019), la compasión consiste en hacerse consciente del sufrimiento propio y de los otros, sin juicios ni críticas. No se niega el sufrimiento ni se huye de él, pero tampoco se queda atrapado por él. Es así como nos propusimos diseñar un programa de mindfulness enfocándonos no solo en la atención concentrada, aceptación, adaptación, pero también en la compasión ya que consideramos que reconocer el sufrimiento propio y de los demás desde un lugar compasivo puedo contribuir en mejorar la calidad de vida de los empleados de Mahou tanto a nivel personal y profesional.

\subsubsection{Beneficios de practicar la compasión}

La compasión y la autocompasión nos producen calma y alegría, activan el sistema de bienestar, nos ayudan a afrontar nuestros fallos, a tomar riesgos, a manejar las críticas y los conflictos, a crear mejores y más armoniosas relaciones. La compasión puede poner en marcha de nuevo el sistema de vínculo que puede haberse cerrado debido a conflictos emocionales, por haber sido abandonado o por haber sufrido abuso. Entonces se reactiva el sistema y aparecen las memorias emocionales relativas a los sucesos que provocaron el cierre pudiendo provocar miedo a sentir la compasión (Gilbert, 2009).

Para practicar la compasión es indispensable tomar conciencia del sufrimiento propio y del de los otros, sin juicio, apego o rechazo, para sentir compasión hacia la otra persona que sufre. Y por encima de todo, para realizar las prácticas de compasión hacen falta unos niveles mínimos de atención plena que se obtienen con la práctica de mindfulness. (García Campayo y Demarzo, 2015). En este sentido, y de acuerdo con Gilbert (2015) para desarrollar la compasión se requieren de tres cualidades: compromiso, para intentar disminuir el sufrimiento propio y el del otro; fortaleza, para tolerar el sufrimiento sin quedarse atrapado en él y mindfulness, como lo menciona previamente García Campayo, para tomar consciencia del sufrimiento del otro y de uno mismo.

Finalmente, a través de nuestro programa "Minuto de Oro" pretendemos profundizar en las practica de mindfulness a través de la creación de 17 píldoras para mejorar la atención concentrada, 10 para mejorar la aceptación y la adaptación y 10 para practicar la compasión. La práctica de estas píldoras les permitirá a los trabajadores de Mahou conseguir habilidades extraordinarias para enfocarse en el momento presente, concentrarse en las actividades laborales, aceptar y adaptarse a las circunstancias cambiantes del entorno. Además, habilidades que les permitan ser más compasivos y amables con ellos mismos especialmente cuando desarrollen los 
ejercicios destinados a las horas de la noche que se enfocan en el amor propio, la autocompasión y la compasión hacia los demás.

\section{METODOLOGÍA}

En la implementación del "Minuto de Oro", se ha utilizado un enfoque meramente cuantitativo experimental, ya que hemos utilizado diversos métodos de investigación, partiendo de un cuestionario a 48 personas, divididas en 6 grupos, tres en la fábrica de Alovera de Mahou San Miguel y tres grupos en su sede central sita en Madrid.

MSM trabaja con su propio programa de excelencia, TOP SEM. Dentro del sistema de excelencia, los equipos se tienen que reunir con una frecuencia establecida y, por supuesto, dependiendo de las características de los miembros del grupo de trabajo (mandos altos, mandos medios y personal de fábrica/administrativos). Es durante el desarrollo de estas TOP SEM donde se ha implementado el MO. Los cuestionarios se entregaron al principio de la implementación del programa, y estaba previsto volver a realizar este cuestionario al final del mismo, pero la crisis del COVID-19 nos lo ha impedido.

\subsection{Diseño del programa}

Para poder diseñar un programa para, y por las personas e implementarlo en un ambiente laboral, buscamos una empresa con potencial y visibilidad a nivel nacional que centre su estrategia en las personas, y cuyo eje principal sea el bienestar de las personas, tanto en el interior del ecosistema, cómo en el exterior.

Cómo ya apuntamos, Mahou San Miguel y a sus trabajadores les definen la pasión por lo que hacen, la calidad, la tradición, la maestría cervecera transmitida de generación en generación a través de sus más de 128 años de historia. Pero, por encima de todo son los valores que les han traído hasta aquí. Impulsan la innovación; disfrutan haciendo las cosas bien y crean negocios y entornos favorables, siempre buscando la excelencia y teniendo en el centro a las personas, y es por ello que decidimos preguntar al Departamento de Personas y Organización si podíamos diseñar e implementar un programa diseñados para ellos.

\subsubsection{Antecedentes}

Aunque existe bastante literatura sobre la teoría y práctica de mindfulness de manera global, solamente hemos encontrado las siguientes investigaciones sobre cómo diseñar e implementar un programa de mindfulness integral en el ámbito laboral, cómo ya mencionamos en el apartado 1.2 del marco teóricodel presente estudio.

El objetivo del primer estudio, Developing leader through minfulness practice, se examinó cómo la capacitación y la práctica de atención plena puede impactar en tres capacidades, identificadas cómo críticas para liderar en el siglo XIX: resiliencia, liderazgo en contextos complejos y colaboración. Los resultados obtenidos sugieren que los líderes ejecutivos pueden aprender y desarrollar la atención plena, siempre y cuándo practiquen mindfulness al menos 10 minutos al día.Reitz, (Megan, Waller, Lee, Chaskalson, Olivier, Rupprecht, Silke ,2020). 
El objetivo del segundo estudio, Workplace mindfulness and its effects on staff auditors'. Audit Quality - Threatening Behaviour, era investigar el efecto de atención plena de los miembros de auditoría en el puesto de trabajo, y la reducción de auditorías en el puesto de trabajo. Los resultados subrayaron la importancia de atención plena en el lugar de trabajo y el aumento de la calidad de auditorías con cierre anticipado. (Herda, Cañon, Young, 2019).

En el siguiente estudio, Leader, Mindfulness and Employee Performance: A sequential mediation model of LMX quality, interpersonal justice and employee stress, cuyo objetivo ha sido encontrar la relación ente la atención plena del líder y el desempeño de los empleados a través de las lentes de la justicia organizacional. En este estudio se planteó varias hipótesis, entre ellas se postuló que cuanto más conscientes son los líderes, mayor es la calidad en la relación entre los líderes y sus empleados. Encontraron que la relación entre la atención plena del líder y la calidad de LMX, estaba medida por el índice de stress de los empleados y su percepción de justicia interpersonal, (Reb, Chatuverdi, Narayanan, kudesia, Ravi S., 2019)

Todas las investigaciones y artículos que hemos encontrado acerca de la implementación y diseño de un programa mindfulness en un entorno laboral, se centran principalmente en un área departamental, o en líderes de equipos de trabajo. La importancia del diseño y desarrollo del programa "Minuto de Oro" radica en que es integral y global para toda la organización, desde el personal técnico/administrativo hasta los mandos altos de la empresa.

\subsubsection{Planificación}

El programa "Minuto de Oro" se enmarca dentro del micro master "Somos Mahoufulness" que se iniciará en septiembre de 2020 con el lanzamiento de un curso de 6 videos de corta duración dedicados a los aspectos básicos del mindfulness, cuyo fin es familiarizar a la población MSM con esta práctica, dirigidos y protagonizado por el Psiquiatra y Prof. Universitario Doctor Javier García Campayo.

A partir del lanzamiento de estos 6 videos (véase apartado 3.2.3 Materiales Principales), hemos diseñado 17 píldoras para realizar al comienzo de todas las reuniones TOPSEM (sistema de excelencia Mahou San Miguel) que se dan en toda la organización. (Véase apartado 1.4.1 Objetivos Generales y específicos de este estudio).

Además, para aquellos individuos que de manera opcional quieran complementar la práctica de mindfulness fuera del ámbito laboral, hemos diseñado 10 píldoras para que, a través de la respiración, emociones y sentidos, incrementar los ratios en aceptación y adaptación, para practicar durante la tarde; y por otro lado, hemos diseñado 10 píldoras para poder incrementar los ratios de compasión.

Cómo ya hemos postulado, tanto en las hipótesis generales cómo en las específicas, creemos que la práctica de atención plena a través de estos materiales incrementará los niveles de concentración en las reuniones TOPSEM, mejorará el nivel de atención plena, aceptación, adaptación y compasión entre la fuerza laboral. 
Para poder corroborar estas hipótesis, organizamos un sistema de medición de tres meses de duración, a 48 trabajadores de MSM, divididos en seis grupos. Tres grupos de estos seis están emplazados en la central de MSM, un grupo de mandos altos, un grupo de mandos medios y finalmente un grupo de administrativos. Por otro lado, los otros tres grupos se encuentran en la fábrica de Alovera, en la provincia de Guadalajara. Estos grupos también están formados por mandos altos, mandos medios y personal técnico de fábrica.

\begin{tabular}{|c|c|}
\hline Mandos Altos Central & Mandos Altos - Alovera \\
\hline Titán, 15 - Martes $10.30 \mathrm{~h}$ & De Lunes a Jueves $14.00 \mathrm{~h} /$ Viernes $11.00 \mathrm{~h}$ \\
\hline Sujeto 1 & Sujeto 1 \\
\hline Sujeto 2 & Sujeto2 \\
\hline & Sujeto 3 \\
\hline Sujeto 3 & Sujeto 4 \\
\hline Sujeto 4 & Sujeto 5 \\
\hline Sujeto 5 & Sujeto 6 \\
\hline Sujeto 6 & Sujeto 7 \\
\hline & Sujeto 8 \\
\hline sujeto $r$ & Suieto 10 \\
\hline Mandos Medios Central & Mandos Medios - Alovera \\
\hline Titán, 15 - Martes $09.30 \mathrm{~h}$ & Lunes, Miércoles \& Jueves 09.30 h \\
\hline Sujeto 1 & Sujeto 1 \\
\hline & Sujeto 2 \\
\hline Sujeto 2 & Sujeto 3 \\
\hline Sujeto 3 & Sujeto 4 \\
\hline Sujeto 4 & Sujeto 5 \\
\hline Sujeto 5 & Sujeto 6 \\
\hline Sujeto 6 & Sujeto 7 \\
\hline \multirow{3}{*}{ Sujeto 7} & Sujeto 8 \\
\hline & Técnicos Base - Alovera \\
\hline & Lunes a Viernes $15.30 \mathrm{~h}$ \\
\hline Administrativos Central & Sujeto 1 \\
\hline Titán, 15 - Martes \& Jueves 12.30 & Sujeto2 \\
\hline Sujeto 1 & Sujeto 3 \\
\hline Sujeto2 & Sujeto 4 \\
\hline & Sujeto 5 \\
\hline Sujeto 3 & Sujeto 6 \\
\hline Sujeto 4 & Sujeto 7 \\
\hline Sujeto 5 & Sujeto 8 \\
\hline Sujeto 6 & Sujeto 9 \\
\hline & Sujeto 10 \\
\hline
\end{tabular}

Los horarios de las reuniones TOPSEM están organizadas en diferentes días de la semana y en diferentes horarios. El calendario de mediciones que organizamos para poder procesar los datos al final del estudio era el siguiente: 

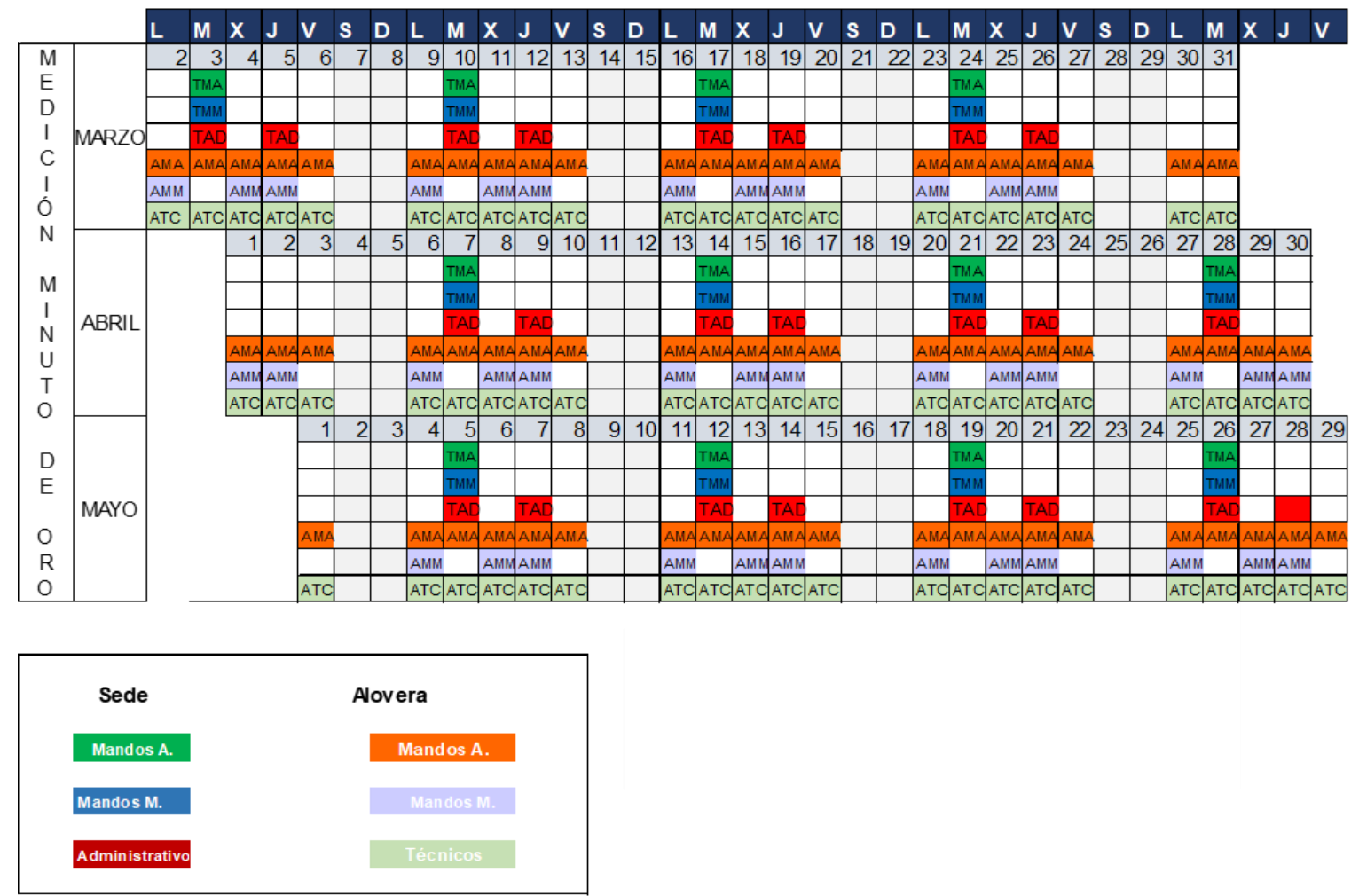

Cómo se observa en el calendario, varias de las reuniones se solapan en días y horas, por lo que, analizando estos datos, decidimos dividirnos las sedes, separándonos en grupos de a dos, y acudiendo a las primeras reuniones con más habitualidad, disminuyendo nuestra asistencia una vez los sujetos se van haciendo más autónomos en la práctica de $\mathrm{MO}$, y al final de la medición, así como muestra la siguiente tabla siguiente tabla de fechas:

Mediciones Minuto de Oro

\begin{tabular}{|c|c|c|c|c|c|c|c|c|c|}
\hline SEMANA & FECHA & Actividad & ugar Presencia & Virtual & $9: 30$ & $10: 30$ & $12: 30$ & $14: 00$ & $15: 30$ \\
\hline \multirow{3}{*}{1} & Martes $03 / 03 / 2020$ & Inicio Lideres Grupo & Titan & Todos & & Mandos Altos & & & \\
\hline & Miércoles 04/03/2020 & Cuestionario inicial & Alovera & & Mandos Medios & & & Mandos Altos & Técnicos Base \\
\hline & Jueves 05/03/2020 & Meditación & Alovera & & Mandos Medios & & & Mandos Altos & Técnicos Base \\
\hline \multirow{3}{*}{2} & Lunes $09 / 03 / 2020$ & Meditación & Alovera & & Mandos Medios & & & Mandos Altos & Técnicos Base \\
\hline & Martes $10 / 03 / 2020$ & Cuestionario inicial & Titan & & Mandos Medios & Mandos Altos & Administrativos & & \\
\hline & Jueves $12 / 03 / 2020$ & Meditación & Alovera & & Mandos Medios & & & Mandos Altos & Técnicos Base \\
\hline \multirow{3}{*}{3} & Martes $17 / 03 / 2020$ & Meditación & Titan & & Mandos Medios & Mandos Altos & Administrativos & & \\
\hline & Lunes $23 / 03 / 2020$ & Meditación & Alovera & & Mandos Medios & & & Mandos Altos & Técnicos Base \\
\hline & Martes $24 / 03 / 2020$ & Meditación & Titan & & Mandos Medios & Mandos Altos & Administrativos & & \\
\hline \multirow{2}{*}{7} & Lunes $13 / 04 / 2020$ & Meditación & Alovera & & Mandos Medios & & & Mandos Altos & Técnicos Base \\
\hline & Martes 14/04/2020 & Meditación & Titan & & Mandos Medios & Mandos Altos & Administrativos & & \\
\hline \multirow{2}{*}{8} & Lunes 20/04/2020 & Meditación & Alovera & & Mandos Medios & & & Mandos Altos & Técnicos Base \\
\hline & Martes 21/04/2020 & Meditación & Titan & & Mandos Medios & Mandos Altos & Administrativos & & \\
\hline \multirow{2}{*}{11} & Lunes $11 / 05 / 2020$ & Meditación & Alovera & & Mandos Medios & & & Mandos Altos & Técnicos Base \\
\hline & Martes $12 / 05 / 2020$ & Meditación & Titan & & Mandos Medios & Mandos Altos & Administrativos & & \\
\hline \multirow{2}{*}{13} & Lunes $25 / 05 / 2020$ & Cuestionario Final & Alovera & & Mandos Medios & & & Mandos Altos & Técnicos Base \\
\hline & Martes 26/05/2020 & Cuestionario Final & Titan & & Mandos Medios & Mandos Altos & \begin{tabular}{|l|} 
Administrativos \\
\end{tabular} & & \\
\hline
\end{tabular}

\begin{tabular}{l|l}
\hline Libre \\
\hline Alovera \\
\hline Titan
\end{tabular}

Así mismo, como indica la tabla anterior, teníamos previsto entregarles el cuestionario de medición para la recolección los datos que nos darían respuesta a las hipótesis planteadas en el marco teórico de este estudio. Medición que no hemos podido llevar acabo dada la crisis del Covid-19 que ya hemos comentado en la 
introducción del marco práctico. Este cuestionario lo desarrollaremos en su totalidad en el apartado 3.2.3 Materiales principales del presente estudio.

Finalmente, y adaptándonos a la crisis que estamos sufriendo a nivel mundial, y a pesar que no hemos podido recolectar los datos que nos darían una respuesta a las hipótesis planteadas, la organización Mahou San Miguel, y en especial su Departamento de Felicidad dirigido por la Doctora Paloma Fuentes, han tomado la decisión de llevar adelante el programa e implementarlo en toda la organización, utilizando la planificación y, en definitiva, este programa, de cara a implementarlo de manera continuada, a partir de septiembre de 2020.

\subsubsection{Materiales principales}

Dado el excesivo peso de cada video, y para poder visualizarlos con la mejor calidad posible, se tiene disponibilidad a cada uno de ellos siguiendo el link para cada uno de ellos que mostramos. La contraseña para poder acceder a ellos es: Minuto_de_Oro

Mindfulness 1 - https://vimeo.com/user120118231/review/441064308/9151a2d2d4

Mindfulness 2 - https://vimeo.com/user120118231/review/441064530/08f068a100

Mindfulness 3 - https://vimeo.com/user120118231/review/441064773/2b48ad6849

Mindfulness 4 - https://vimeo.com/user120118231/review/441064924/0d7b79a0a8

Mindfulness 5 - https://vimeo.com/user120118231/review/441065078/c0a5133e67

Mindfulness 6 - https://vimeo.com/user120118231/review/441065193/8c2b17a0a6

El programa que hemos diseñado y desarrollado consta de 37 píldoras de atención plena para poder practicar en la vida cotidiana, ya que la vida cotidiana es lo único que existe, Jon Kabat-Zinn (2107).

Estas píldoras de atención al presente las hemos dividido en 3 apartados para abordar en diferentes momentos del día o ante diferentes necesidades emocionales:

$>$ Atención plena - Sobre estas píldoras se ha hecho la medición. Se han practicado al principio de cada reunión TOP SEM.

> Aceptación - Hemos desarrollado estas píldoras para que aquellas personas que hayan querido seguir practicando atención plena en su día a día. Son opcionales, y aunque recomendamos hacerlas al mediodía se pueden practicar cuando sea necesario.

> Agradecimiento - Hemos desarrollado estas píldoras para que aquellas personas que hayan querido seguir practicando atención plena en su día a día. Son opcionales, y aunque recomendamos hacerlas por la noche, se pueden practicar cuando sea necesario.

Para el diseño y posterior fabricación del producto se han seguido varios pasos comunes a todas las píldoras, y que solamente varían en algunos pequeños detalles:

\section{Color}

Las píldoras de atención plena se han diseñado en amarillo, en el color del sol. Provoca buen humor y alegría, es vigorizante pero no agresivo. Según la 
coloterapia, estimula la vista y las actividades intelectuales, reduce la fatiga y calma los nervios. Expresa animación, alegría, excitación y sentimientos de afecto, (Universidad Europea de Madrid).

Las píldoras de aceptación se han diseñado en verde, en el color de la naturaleza. Calma la excitación, ayuda contra la fatiga. Expresa salud, paz, seguridad y esperanza, (Universidad Europea de Madrid).

Las píldoras de agradecimiento han sido diseñadas en azul, en el color del mar. Es un color que expresa calma, seguridad, paz, confianza. (Universidad Europea de Madrid).

\section{Tamaño}

Para las versiones físicas se han utilizado dos tamaños, A-4 para las píldoras de atención plena, y A-5 para las de aceptación y las de agradecimiento.

Las píldoras de atención plena, como ya hemos apuntado, se utilizan en las reuniones TOPSEM. En estas reuniones se utilizan panales dónde debe estar visible toda la información necesaria para desarrollar la reunión de excelencia. Para tener una mejor visualización de la píldora, sin ocupar mucho espacio hemos optado por un tamaña A-4.

Por otro lado, las píldoras de aceptación y agradecimiento deben ser transportables a otros entornos que no sea el laboral, y es por eso que hemos optado por un tamaña A-5, para que se visualice toda la información, y a la vez fáciles de transportar sin ocupar mucho espacio.

\section{BIBLIOGRAFÍA}

DeConceptos. (2020). Obtenido de https://deconceptos.com/cienciassociales/compasion

Editorial Definición MX. (2013). Adaptación . Obtenido de Definición MX: https://definicion.mx/adaptacion/

Elices , M., \& Cordero , M. (2011). La terapia dialéctico conductual para el tratamiento del trastorno límite de personalidad. Recuperado el Mayo de 2020, de Psicología, Conocimiento y Sociedad https://revista.psico.edu.uy/index.php/revpsicologia/article/view/67

Escuela Española de Desarrollo Transpersonal. (s.f.). (s.f.). Escuela Española de Desarrollo Transpersonal. . Obtenido de Guía de iniciación a la Meditación Transpersonal.: Recuperado de https://escuelatranspersonal.com/wpcontent/uploads/2018/10/GUI\%C3\%ACA-INICIACIO\%C3\%ACN-A-

Foster , J. (2018). La más profunda aceptación: Despertar radical en la vida ordinaria. España: Sirio S.A.

García Campayo , J. (2019). Mindfulness: Nuevo manual Práctico: El camino de la atención plena. España: Siglantana. 
García Campayo , J., \& Demarzo. (2019). La práctica de la compasión: Amabilidad con los demás y con uno mismo. Barcelona : Siglantana.

Herda , D. N., Cañon , N. H., \& Young, R. F. (2019). EBSCOhost. Obtenido de Behavioral Research in Accounting: http://web.b.ebscohost.com/ehost/detail/detail?vid=6\&sid=498610bb-2ea6-4e5c84fb-2de5ebab9133\%40pdc-vsessmgr03\&bdata $=$ JnNpdGU9ZWhvc3QtbGl2ZQ\%3d\%3d\#AN=137857571\&db=b $\underline{s h}$

Kabat-Zinn, J. (2007). La práctica de la atención plena. Barcelona: Kaíros.

Kabat-Zinn, J. (2009). Mindfulness en la vida cotidiana. Barcelona España: Ediciones Paidós lbérica.

LeMaster, C. (2018). TruEdge consulting. Obtenido de TruEdge: (http://www.truedgeconsulting.com/innovation/vuca/).

Nhat Hanh, T., \& Cheung, L. (2001). Saborear, Mindfulness para comer y vivir bien . Madrid : Espasa Libros.

Raffino, M. E. (2019). Adaptación de los seres vivos . Obtenido de Concepto : https://concepto.de/adaptacion-de-los-seres-vivos/

Ramos Díaz , N., Enríquez Anchondo , H., \& Recondo Pérez, O. (2012). Inteligencia Emocional Plena : Mindfulness y la gestión eficaz de las emociones. Barcelona: Kaíros.

Ramos Díaz , N., Recondo Peréz , O., \& Enríquez Anchondo, H. (2012). Practica de la inteligencia emocional plena: Mindulness para regular nuestras emociones. Barcelona: Kaíros.

Real Academia Española. (2001). Diccionario de la lengua española. Recuperado el 26 de 04 de 2020, de Real Academia Española: https://www.rae.es/drae2001/aceptaci\%C3\%B3n

Real Academia Española. (s.f.). Adaptación. Diccionario de la Real Academia Española (23. ${ }^{a}$ ed.). Recuperado de https://dle.rae.es/adaptación

Real Academia Española. (2001). Diccionario de la lengua española. Recuperado de https://dle.rae.es/compasión

Reb, J., Chaturvedi, S., Narayanan, J., \& Kudesia, R. S. (2019). EBSCOhost. Obtenido de Journal of Business Ethics: http://web.b.ebscohost.com/ehost/detail/detail ?vid=8\&sid=498610bb-2ea6-4e5c84fb-2de5ebab9133\%40pdc-vsessmgr03\&bdata=JnNpdGU9ZWhvc3QtbGl2ZQ\%3d\%3d\#AN=140033568\&db=ef $\underline{t}$ 
Reitz , M., Waller, L., Chaskalson, M., Olivier, S., \& Rupprecht, S. (2020). EBSCOhost. Obtenido de Journal of Management Development : http://web.b.ebscohost.com/ehost/detail/detail?vid=4\&sid=498610bb-2ea6-4e5c84fb-2de5ebab9133\%40pdc-vsessmgr03\&bdata=JnNpdGU9ZWhvc3QtbGl2ZQ\%3d\%3d\#AN=142437475\&db=b $\underline{\text { sh }}$

Rodríguez de Medina Quevedo, Q. (Volumen 1. Páginas 132-137 de 2012). ReiDoCrea. Obtenido de Revista electrónica de investigación Docencia Creativa: https://digibug.ugr.es/bitstream/handle/10481/21978/ReiDoCrea-Vol.1-Art.18Rodriguez.pdf?sequence $=1$ \&isAllowed $=y$

Trainor, K. (2006). Budismo: Principios, práctica, rituales y escrituras sagradas. Aspectos históricos, religiosos y sociales. Barcelona: Blume.

Trowbridge, K., Lawson, L. M., Andrews, S., Pecora, J., \& Boyd, S. (2017). EBSCOhost. Obtenido de Health \& Social Work : http://web.b.ebscohost.com/ehost/detail/detail?vid=12\&sid=498610bb-2ea6-4e5c84fb-2de5ebab9133\%40pdc-Vsessmgr03\&bdata=JnNpdGU9ZWhvc3QtbGl2ZQ\%3d\%3d\#AN=125985622\&db=p $\underline{\mathrm{bh}}$

Vallejos , M. A. (2006). Atención Plena, Mindfulness. Edu Psukhé. Revista de Psicología y Psicopedagogía, 5 (2), 231 -253.

Yu, L., \& Zellmer-Bruhn, M. (2018). EBSCOhost. Obtenido de Academy of Management Journal http://web.b.ebscohost.com/ehost/detail/detail?vid=10\&sid=498610bb-2ea6-4e5c84fb-2de5ebab9133\%40pdc-vsessmgr03\&bdata=JnNpdGU9ZWhvc3QtbGl2ZQ\%3d\%3d\#AN=128057431\&db=b $\underline{s h}$

\section{AUTORES}

Lenny Fabiola León Montaño

EAE Business School, España.

\section{Alexis Tatyana Rubio Osorio \\ EAE Business School, España.}

Jessica Carmen Carolina Valle Miranda

EAE Business School, España.

Isabel María Cobreros Romera

EAE Business School, España. 